\title{
Morfometria de plantios de Dipteryx odorata Aubl Willd (Cumaru) no Oeste do Pará
}

\author{
Jéssica Aline Godinho da Silva $\bigotimes^{1 *}$ Daniela Pauletto ${ }^{1}$ Adria Fernandes da Silva ${ }^{1}$ Cezarina do \\ Socorro de Souza Carvalho ${ }^{1}$ Hailla Gisely Gomes do Nascimento ${ }^{1}$
}

${ }^{1}$ Universidade Federal do Oeste do Pará, R. Vera Paz, s/n (Unidade Tapajós), Salé, | CEP 68040-255,| Santarém, PA, Brasil

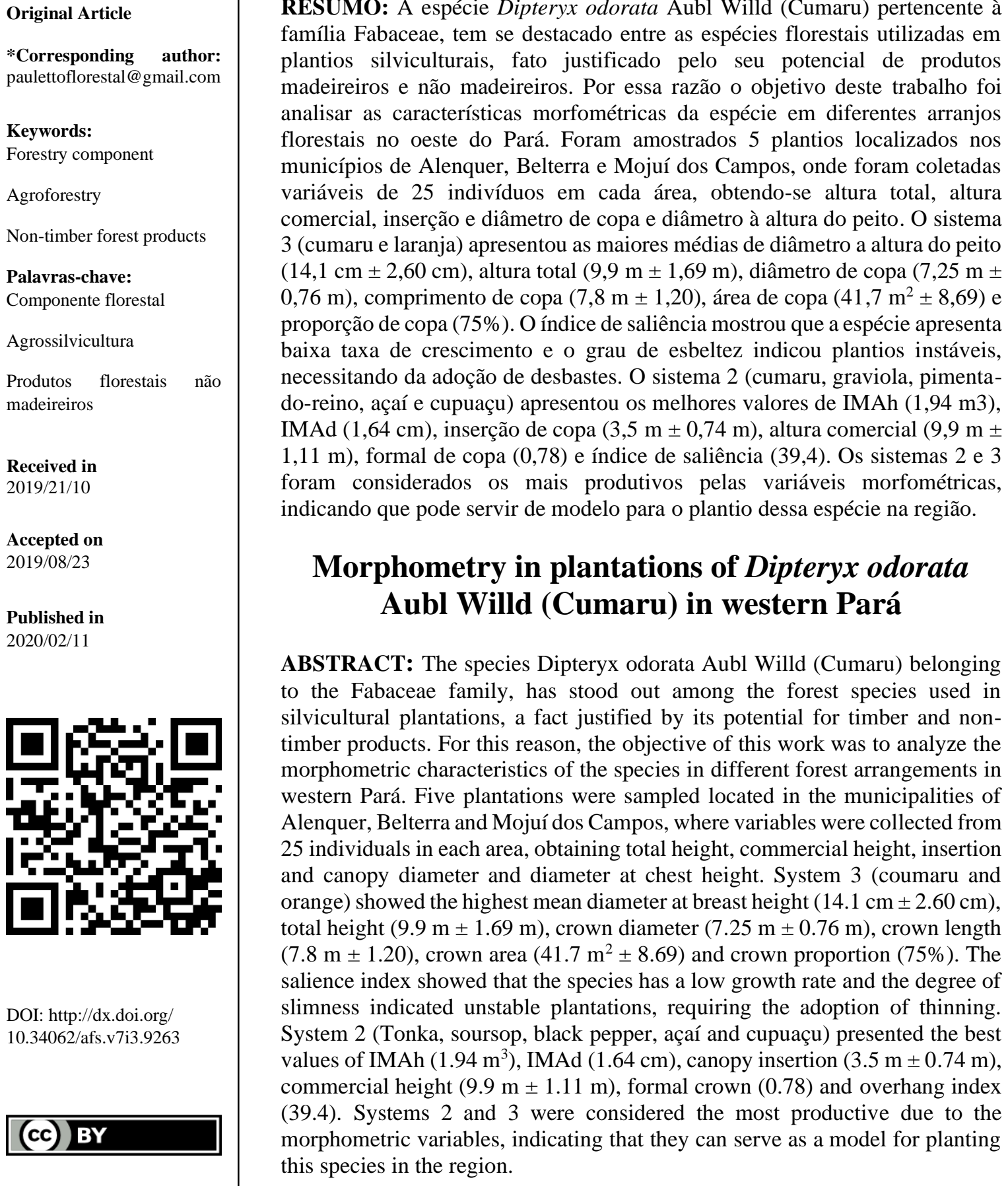

DOI: http://dx.doi.org/ 10.34062/afs.v7i3.9263

(cc) BY família Fabaceae, tem se destacado entre as espécies florestais utilizadas em plantios silviculturais, fato justificado pelo seu potencial de produtos madeireiros e não madeireiros. Por essa razão o objetivo deste trabalho foi analisar as características morfométricas da espécie em diferentes arranjos florestais no oeste do Pará. Foram amostrados 5 plantios localizados nos municípios de Alenquer, Belterra e Mojuí dos Campos, onde foram coletadas variáveis de 25 indivíduos em cada área, obtendo-se altura total, altura comercial, inserção e diâmetro de copa e diâmetro à altura do peito. O sistema 3 (cumaru e laranja) apresentou as maiores médias de diâmetro a altura do peito $(14,1 \mathrm{~cm} \pm 2,60 \mathrm{~cm})$, altura total $(9,9 \mathrm{~m} \pm 1,69 \mathrm{~m})$, diâmetro de copa $(7,25 \mathrm{~m} \pm$ $0,76 \mathrm{~m})$, comprimento de copa $(7,8 \mathrm{~m} \pm 1,20)$, área de copa $\left(41,7 \mathrm{~m}^{2} \pm 8,69\right) \mathrm{e}$ proporção de copa $(75 \%)$. O índice de saliência mostrou que a espécie apresenta baixa taxa de crescimento e o grau de esbeltez indicou plantios instáveis, necessitando da adoção de desbastes. O sistema 2 (cumaru, graviola, pimentado-reino, açaí e cupuaçu) apresentou os melhores valores de IMAh (1,94 m3), IMAd $(1,64 \mathrm{~cm})$, inserção de copa $(3,5 \mathrm{~m} \pm 0,74 \mathrm{~m})$, altura comercial $(9,9 \mathrm{~m} \pm$ $1,11 \mathrm{~m})$, formal de copa $(0,78)$ e índice de saliência $(39,4)$. Os sistemas 2 e 3 foram considerados os mais produtivos pelas variáveis morfométricas, indicando que pode servir de modelo para o plantio dessa espécie na região.

\section{Morphometry in plantations of Dipteryx odorata Aubl Willd (Cumaru) in western Pará}

\begin{abstract}
The species Dipteryx odorata Aubl Willd (Cumaru) belonging to the Fabaceae family, has stood out among the forest species used in silvicultural plantations, a fact justified by its potential for timber and nontimber products. For this reason, the objective of this work was to analyze the morphometric characteristics of the species in different forest arrangements in western Pará. Five plantations were sampled located in the municipalities of Alenquer, Belterra and Mojuí dos Campos, where variables were collected from 25 individuals in each area, obtaining total height, commercial height, insertion and canopy diameter and diameter at chest height. System 3 (coumaru and orange) showed the highest mean diameter at breast height $(14.1 \mathrm{~cm} \pm 2.60 \mathrm{~cm})$, total height $(9.9 \mathrm{~m} \pm 1.69 \mathrm{~m})$, crown diameter $(7.25 \mathrm{~m} \pm 0.76 \mathrm{~m})$, crown length $(7.8 \mathrm{~m} \pm 1.20)$, crown area $\left(41.7 \mathrm{~m}^{2} \pm 8.69\right)$ and crown proportion $(75 \%)$. The salience index showed that the species has a low growth rate and the degree of slimness indicated unstable plantations, requiring the adoption of thinning. System 2 (Tonka, soursop, black pepper, açaí and cupuaçu) presented the best values of IMAh $\left(1.94 \mathrm{~m}^{3}\right)$, IMAd $(1.64 \mathrm{~cm})$, canopy insertion $(3.5 \mathrm{~m} \pm 0.74 \mathrm{~m})$, commercial height $(9.9 \mathrm{~m} \pm 1.11 \mathrm{~m})$, formal crown $(0.78)$ and overhang index (39.4). Systems 2 and 3 were considered the most productive due to the morphometric variables, indicating that they can serve as a model for planting this species in the region.
\end{abstract}

RESUMO: A espécie Dipteryx odorata Aubl Willd (Cumaru) pertencente à 


\section{Introdução}

A Dipteryx odorata Aubl Willd ou cumaru, como popularmente é chamado na região Oeste do Pará, é uma espécie da família Fabaceae e apresenta outras diversas nomenclaturas de acordo com a região em que se encontra como, cumaru do Amazonas, cumbari sarrapia, cumaru roxo, cumaru ferro, cumaru da folha grande, cumaru verdadeiro, cumari e internacionalmente é conhecido como Tonka (Carvalho 2009). É uma árvore de grande porte, que chega a atingir 30 metros de altura e ocorre na mata primária de terra firme e nas várzeas, desde o Acre até o Maranhão, podendo ser vista também em países que fazem fronteira com o Brasil, como a Venezuela e as Guianas (Silvestre 2006). Sua frutificação começa a ocorrer a partir dos 4 a 5 anos de idade geralmente entre os meses de abril e julho. (Carvalho 2009)

Segundo o IBGE (2016), a extração de amêndoas de Cumaru no brasil, passou de 97 toneladas no ano de 2015, para 145 toneladas no ano de 2016, tendo uma variação de 49,5\%. É uma espécie com diversos fins econômicos, sendo utilizada desde a alimentação humana e animal até na produção de corantes, óleos, perfumes, inseticidas, apresentando ainda uso medicinal, agronômico (enriquecimento de solos) e ornamental (Ferreira et al. 2004).

As amêndoas dos frutos são aromáticas, de onde se extrai um óleo essencial chamado Cumarina, muito utilizado em perfumaria (Silva et al. 2010). Além das amêndoas, sua madeira pode ser empregada em diferentes fins, desde a fabricação de móveis até a construção civil, pois apresenta propriedades mecânicas favoráveis (Loureiro et al. 1979). Ainda segundo o autor, na casca encontra-se uma propriedade medicinal muito utilizada como antiespasmódica, tônica e eficaz moderador dos movimentos cardíacos e da respiração. Seus frutos maduros caem das árvores e são recolhidos no solo para a extração das sementes gerando renda a pequenos produtores rurais (Silva et al. 2018).

No Oeste do Pará, os principais produtos não madeireiros comercializados para fins medicinais são os óleos de copaíba, andiroba, pau rosa e o cumaru (Gonçalves et al. 2012). Para Rêgo (2014) utilizar esses produtos florestais, ditos não madeireiros, oriundos do manejo das florestas nativas, de plantações ou de sistemas agroflorestais é uma forma de minimizar os efeitos dos impactos ambientais negativos e ainda colaborar para a sustentabilidade. Uma floresta plantada pode ser manejada de acordo com o fim que se deseja, podendo alcançar diferentes mercados de produtos florestais e o cumaru, por possuir um rápido crescimento e um fuste de bom porte, pode ser utilizado consorciado com espécies de porte menor e tolerantes ao sombreamento (Santos 2002).

Para Moreira et al. (2017) é de fundamental importância que o segmento de florestas plantadas seja mais explorado considerando seu potencial produtivo. Roman et al. (2009) esclarece que no cenário em que se observa o uso cada vez maior de espécie florestais nativas sendo manejadas, o conhecimento da morfometria e da dinâmica das formas das árvores, torna-se imprescindível para aprimorar as intervenções silviculturais, principalmente quando se deseja tornar efetiva a utilização dessas espécies com interesses econômicos. Além disso podemos prever o espaço necessário para cada árvore ao longo de seu desenvolvimento, julgar o grau de concorrência entre indivíduos de um povoamento, bem como nos dar informações acerca da estabilidade, vitalidade e produtividade de cada indivíduo (Durlo 2001).

Durlo e Denardi (1998) estudando a espécie Cabralea canjerana, descreveram as principais características morfométricas utilizadas até hoje, como proporção de copa, que indica a fração (\%) que a copa abrange em relação à árvore; grau de esbeltez, que caracteriza a estabilidade das árvores; índice de saliência, que expressa quantas vezes o diâmetro de copa é maior que o DAP; índice de abrangência, que pode ser usado como indicador de desbaste ao longo da vida do povoamento e; formal de copa, que serve como critério para a marcação de desbastes.

Sabendo da importância dos estudos morfométricos em povoamentos florestais, o objetivo deste trabalho foi estudar o comportamento dessas características em diferentes arranjos florestais de cumaru, descrevendo as que mais se sobressaíram em cada sistema adotado, bem como analisar se favorecem a produção de madeira ou de sementes, para desta forma, fornecer subsídios ao manejo da espécie em diferentes sistemas de produção.

\section{Material e Métodos}

As áreas estudadas configuram 5 plantios de cumaru localizados nos municípios de Alenquer, Belterra e Mojuí dos Campos, localizado no Oeste do Pará. Segundo estudo de Alvarez et al (2013) esta região apresenta precipitação anual de 1.900 a 2.200 mm e tipo climático de Köppen Am, com temperatura médias anuais de 25 a 27 graus Celsius e altitude variando de 81 a $316 \mathrm{~m}$.

A tipologia da vegetação é denominada Floresta Ombrófila Densa (IBGE 2004). Na região ocorrem oito tipos de solo, no entanto há a predominância de latossolo e argissolo que correspondem a $81 \%$ do estado do Pará (EMBRAPA 2016).

As informações sobre o manejo dos povoamentos foram obtidas através de entrevistas com os produtores rurais, onde foi questionado as formas de condução, a finalidade, e se era adotado algum tipo de tratamento silvicultural e ou adubação do solo. Para composição da descrição das áreas, 
foram coletadas as seguintes informações: idade, tamanho da área, espaçamento e número de espécies.

Para a amostragem foram selecionados três povoamentos florestais no município de Alenquer, um em Mojuí dos Campos e um em Belterra, onde o componente florestal encontrava-se implantado há menos de 10 anos, coletando-se variáveis de 25 indivíduos em cada sistema. Para esta seleção foram desconsideradas as árvores cultivadas nas bordas dos plantios e, a cada medição, excluiu-se o próximo indivíduo, de maneira configurar uma amostragem sistemática.
Assim como no estudo de Condé et al. (2013), as áreas estudadas apresentaram histórico de uso e características de vegetações originais distintas, ressaltando que esses fatores podem contribuir para as diferentes características nos sistemas.

A amostragem resultou em 4 plantios organizados de forma consorciada, ou seja, houve integração na mesma área, com outras espécies principalmente frutíferas, e um plantio homogêneo (Quadro 1). A combinação de espécies ocorreu principalmente em função da demanda do mercado regional para estes produtos. A idade dos plantios variou de 6 a 10 anos com áreas de 0,1 a 1,0 hectare.

Quadro 1: Caracterização geral das áreas de povoamentos florestais de Dipteryx odorata no Oeste do Pará.

\begin{tabular}{|c|c|c|c|c|c|}
\hline Sistema & Espécies no arranjo & Município & $\begin{array}{c}\text { Área } \\
\text { plantada } \\
\text { (ha) }\end{array}$ & $\begin{array}{c}\text { Espaçamento entre } \\
\text { cumaru (m) }\end{array}$ & $\begin{array}{c}\text { Idade } \\
\text { plantio do } \\
\text { cumaru } \\
\text { (anos) }\end{array}$ \\
\hline 1 & Cumaru e abacaxi & Alenquer & 0,1 ha & $5,5 \times 4,5\left(25 \mathrm{~m}^{2}\right)$ & 6 \\
\hline 2 & $\begin{array}{c}\text { Cumaru, cupuaçu, } \\
\text { açaí, graviola, banana } \\
\text { e pimenta }\end{array}$ & Belterra & 1,0 ha & $8 \times 6\left(48 \mathrm{~m}^{2}\right)$ & 7 \\
\hline 3 & Cumaru e laranja & $\begin{array}{c}\text { Mojuí dos } \\
\text { Campos }\end{array}$ & 0,5 ha & $4 \times 8\left(32 \mathrm{~m}^{2}\right)$ & 9 \\
\hline 4 & Cumaru e limão & Alenquer & 0,9 ha & $10 \times 8,5\left(85 \mathrm{~m}^{2}\right)$ & 8 \\
\hline 5 & Cumaru & Alenquer & 0,5 ha & $6 \times 6\left(36 \mathrm{~m}^{2}\right)$ & 10 \\
\hline
\end{tabular}

No sistema 1 havia vegetação secundária antes do plantio que foi derrubada e queimada para cultivo de mandioca. Posteriormente, foi inserido o sistema agroflorestal composto por cumaru e abacaxi (Ananas comosus), que é mantido com capinas periódicas esporádicas e sem uso de herbicida. Não há aplicação de adubação nos dois cultivos.

No sistema 2 houve a retirada da vegetação nativa e queima para implantação de pecuária bovina, atividade que foi desenvolvida por 5 anos. Atualmente, apresenta um sistema agroflorestal composto por cumaru, pimenta-do-reino (Piper nigrum), banana (Musa spp), açaí (Euterpe oleracea), graviola (Annona muricata) e cupuaçu (Theobroma grandiflorum) onde há controle mecânico (roçadeira) e químico (herbicidas) de plantas espontâneas nas entre linhas de plantio. A adubação é realizada esporadicamente somente nos exemplares de pimenta do reino. Os exemplares de cumaru sofreram podas parciais de ramos laterais nos primeiros 3 anos conforme a disponibilidade de mão-de-obra do produtor.

O sistema 3 possui área de 0,5 hectare e nos primeiros 3 anos houve a introdução de espécies agrícolas (mandioca e abacaxi) entre as espécies perenes. Atualmente apresenta o arranjo composto por cumaru e laranja (Citrus sinensis L.). A limpeza é feita com roçagem e não ocorre adubação nos cultivos. Não são aplicadas podas de condução no cumaru.
O plantio no sistema 4 foi realizado após a remoção da vegetação secundária por corte e queima. O sistema tem idade de 8 anos e é composto por cumaru e limão (Citrus limonium) entre as linhas de plantio em espaçamento de 6x6 metros. Para ambos se utilizou adução orgânica (esterco bovino) na cova e a manutenção do cumaru é feita com podas periódicos dos galhos mais baixos.

No sistema 5 tem-se inicialmente, após corte e queima da vegetação secundária, o cultivo do milho (Zea mays) em consórcio ao cumaru nos primeiros 2 anos. Após esse período a área ficou abandonada por cerca de 5-6 anos, quando então houve a retomada das atividades na propriedade com roçagem para favorecer o desenvolvimento do cumaru. Não foi relatado correção do solo nem qualquer tipo de adubação no plantio.

Nos povoamentos avaliados coletou-se as variáveis diâmetro à altura do peito (DAP), medido a 1,3 $\mathrm{m}$ do solo e diâmetro de copa (DC) dos exemplares amostrais de cumaru, através de fita métrica. Já a altura total (HT) e a inserção de copa (IC), relativo á base da árvore até a primeira ramificação, foram obtidas através do aparelho Vertex IV e Transponder T3, conforme ilustrado na figura 1 .

Para as variáveis IC e AC utilizou-se o modelo (Figura 1) proposto por Baloneque (2017) que observou que, em muitos casos, estas variáveis divergem de posição nas árvores. Desta forma o comprimento de copa (CC) foi determinado pela 


\section{Silva et al.}

diferença entre altura total e altura de inserção da copa.

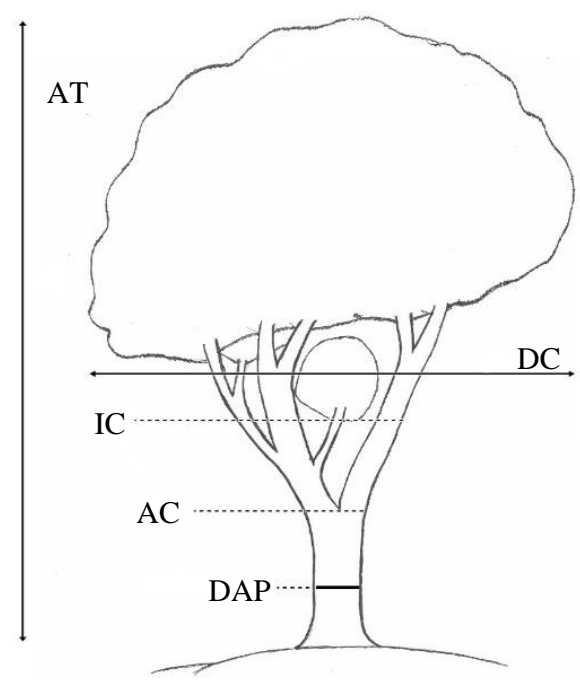

Onde:

$\mathrm{AT}=$ Altura total $(\mathrm{m})$

$\mathrm{DC}=$ Diâmetro de copa $(\mathrm{m})$

$\mathrm{IC}=$ Inserção de copa $(\mathrm{m})$

$\mathrm{AC}=$ Altura comercial $(\mathrm{m})$

$\mathrm{DAP}=$ Diâmetro a altura do peito $(\mathrm{cm})$

Figura 1: Modelo ilustrativo de uma árvore e suas características dimensionais (Baloneque 2017)

Para obtenção do DC foram realizadas duas medições de diâmetro de copa por árvore (sentido leste-oeste e norte-sul) para obtenção do valor médio desta variável.

Para a análise morfométrica utilizou-se os seguintes índices: área de proporção de copa, grau de esbeltez, índice de saliência, índice de abrangência e formal de copa (Quadro 2) baseado no estudo de Condé et al (2013).

Quadro 2. Variáveis morfométricas em povoamentos florestais de Dipteryx odorata (Cumaru) no oeste do Pará.

\begin{tabular}{|ccc|}
\hline Índice/variável & Abreviatura & Fórmula \\
\hline Área de copa & $\mathrm{AC}$ & $\left(\pi^{*} \mathrm{DC}^{2}\right) / 4$ \\
Comprimento de copa & $\mathrm{CC}$ & $\mathrm{AT}-\mathrm{IC}$ \\
Formal de copa & $\mathrm{FC}$ & $\mathrm{DC} / \mathrm{CC}$ \\
Grau de esbeltez & $\mathrm{GE}$ & $\mathrm{AT} / \mathrm{DAP}$ \\
Índice de abrangência & $\mathrm{IA}$ & $\mathrm{DC} / \mathrm{AT}$ \\
Índice de saliência & $\mathrm{IS}$ & $\mathrm{DC} / \mathrm{DAP}$ \\
Proporção da copa & $\mathrm{PC}$ & $(\mathrm{CC} / \mathrm{AT})^{*} 100$ \\
\hline
\end{tabular}

A partir das variáveis AT e DAP e idade da espécie foi calculado o incremento médio anual em altura (IMAh) e em diâmetro (IMAd).

$\mathrm{Na}$ análise dos dados, foram utilizadas planilhas eletrônicas. Para os índices de morfometria foi utilizado Assistat versão® 7.7, aplicando-se o teste de normalidade das variáveis para posterior análise de variância (ANOVA) e, quando necessário, teste de Tukey ao nível de 5\% de probabilidade de erro. Para os dados de DAP, DC e AT foi constatado normalidade enquanto, para as variáveis AC e IC houve transformação usando a escala logarítmica para atingir tal parâmetro.

\section{Resultados e Discussão}

Adv. For. Sci, Cuiabá, v. 7, n. 3, p. 1171-1180, 2020
O sistema 3 foi o que apresentou as maiores médias para DAP e DC $(14,1 \mathrm{~cm}$ e $7,2 \mathrm{~m}$, respectivamente), diferindo significativamente da demais áreas (Tabela 1). As menores médias para as mesmas variáveis foram observadas no sistema 4, onde, comparadas aos demais sistemas apresentou as menores médias para a variável DAP e DC.

No entanto, apesar do resultado positivo para o sistema 3, os mesmos foram inferiores aos encontrados para a mesma espécie por Capucho et al. (2016) no Oeste do Pará, onde plantios mais jovens apresentaram médias de 27 e $37 \mathrm{~cm}$ de DAP. Esta diferença pode estar relacionada ao sítio, aos tipos de tratamentos que são utilizados assim como a idade do povoamento. No sistema 2, um sistema agroflorestal com 6 espécies e 7 anos de 
Silva et al.

implantação, o resultado encontrado foi similar ao encontrado por Lima Junior et al. (2009) em plantio puro.

Tabela 1. Médias de diâmetro a altura do peito (DAP) e diâmetro de copa (DC) da espécie Dipteryx odorata em povoamentos florestais no Oeste do Pará. Onde: médias seguidas de mesma letra, na coluna, não diferem estatisticamente entre si pelo teste de Tukey a 5\% de probabilidade.

\begin{tabular}{ccccc}
\hline Sistema & DAP $(\mathbf{c m})$ & Desvio Padrão & DC $(\mathbf{m})$ & Desvio Padrão \\
\hline 1 & $8,9 \mathrm{c}$ & 1,51 & $5,1 \mathrm{~b}$ & 0,77 \\
2 & $12,3 \mathrm{~b}$ & 2,92 & $4,8 \mathrm{bc}$ & 1,40 \\
3 & $14,1 \mathrm{a}$ & 2,60 & $7,2 \mathrm{a}$ & 0,76 \\
4 & $6,3 \mathrm{~d}$ & 2,64 & $3,1 \mathrm{~d}$ & 1,54 \\
5 & $8,8 \mathrm{c}$ & 2,86 & $4,1 \mathrm{~cd}$ & 1,26 \\
\hline
\end{tabular}

Observou-se que nos sistemas 1,2 e 3, os quais apresentaram as maiores médias de DC, em geral, as copas aparentemente estão em competição por espaço na linha de plantio, mostrando que os espaçamentos adotados para cada sistema não atenderiam as necessidades de cada indivíduo para o seu pleno desenvolvimento. No entanto são estes os sistemas que apresentam também maior crescimento em At.

Os sistemas com maiores espaçamentos entre as árvores de $D$. odorata apresentados nesse trabalho geraram os menores valores em DAP e DC, indo contra as conclusões de muitos autores. Klein et al. (2017) sugerem que para maiores DC há a necessidade de maior espaço lateral para $o$ crescimento e desenvolvimento das árvores, ou seja, precisam de espaçamentos adequados para que possam demonstrar sua capacidade de competição.

A produção de amêndoas também é favorecida por copas mais frondosa e torna-se um fator decisivo nos plantios regionais visto que a comercialização deste produto tem ganhado destaque nos últimos anos e, com evidenciado por Silva et al (2018) indicado uma importante fonte de renda aos produtores. Estudo de Dionísio et al. (2018) evidenciam ainda que a determinação da variável DC é de fundamental importância, pois permite realizar a projeção do espaço a ser reservado para a árvore, de forma a garantir seu bom desenvolvimento.

Outro fator que pode ter levado os maiores espaçamentos a menores taxas de crescimento foi o tipo de sitio, a escolha de espécies que integram estes sistemas e os tratos silviculturas destas, como é evidente no sistema 4 , com 8 anos de idade, que apresentou as menores médias de DAP e DC e, em comparação aos sistemas 1 e 2, que são povoamentos mais jovens (6-7 anos) estes obtiveram médias maiores para essas variáveis. Sugere-se que este comportamento está ligado ao sítio já que o sistema 5 , inserido na mesma propriedade, também apresenta médias baixas para estas variáveis. Somando-se a isto há a ocorrência de competição de recursos com o limão, que apresentando copa e altura maiores que o cumaru, causando competição por espaço já que as copas são muito frondosas o que dificulta o pleno desenvolvimento das copas consequentemente isso reflete no DAP. Tonini e Arco-Verde (2005) ressaltam que é importante a escolha minuciosa das espécies a serem implantadas em um sistema consorciado, para que as espécies implantadas atinjam altas produtividades com harmonia sinergética entre as plantas.

A altura total dos indivíduos variou entre 5,3 $\mathrm{m}$ a $9,9 \mathrm{~m}$, sendo que os maiores valores foram encontrados no sistema 2 e 3 (9,9 e 9,6 m) não diferindo estatisticamente entre si (Tabela 2). Estes valores foram inferiores ao aferido em plantio do tipo silvipastoril de 11 anos, com a mesma espécie, que foi de 14,3 m (Baloneque 2017). Outro estudo com cumaru na região encontrou médias para altura total, em plantios com 6 anos, de 5,6 m (Capucho et al. 2016) que se configura inferior à média encontrada para o sistema 1 também de 6 anos que obteve média de $8,8 \mathrm{~m}$.

Tabela 2. Médias de altura total (AT), inserção de copa (IC) e altura comercial (AC) da espécie Dipteryx odorata em povoamentos florestais no Oeste do Pará. Onde: médias seguidas de mesma letra, na coluna, não diferem estatisticamente entre si pelo teste de Tukey a $5 \%$ de probabilidade.

\begin{tabular}{ccccccc}
\hline Sistema & AT $(\mathbf{m})$ & $\begin{array}{c}\text { Desvio } \\
\text { Padrão }\end{array}$ & IC (m) & $\begin{array}{c}\text { Desvio } \\
\text { Padrão }\end{array}$ & AC (m) & $\begin{array}{c}\text { Desvio } \\
\text { Padrão }\end{array}$ \\
\hline 1 & $8,1 \mathrm{~b}$ & 0,78 & $2,0 \mathrm{c}$ & 0,38 & $0,6 \mathrm{~d}$ & 0,47 \\
2 & $9,9 \mathrm{a}$ & 1,69 & $3,5 \mathrm{a}$ & 0,74 & $2,8 \mathrm{a}$ & 1,11
\end{tabular}




$\begin{array}{lllllll}3 & 9,6 \mathrm{a} & 1,38 & 1,8 \mathrm{c} & 0,40 & 0,7 \mathrm{~cd} & 0,35 \\ 4 & 5,3 \mathrm{c} & 1,40 & 2,5 \mathrm{~b} & 0,51 & 1,3 \mathrm{c} & 0,84 \\ 5 & 7,0 \mathrm{~b} & 1,43 & 2,5 \mathrm{~b} & 0,62 & 1,9 \mathrm{~b} & 0,73\end{array}$

Para a IC e AC o sistema 2 apresentou as melhores médias (3,5 e 2,8 m, respectivamente) diferindo das demais áreas (Tabela 2). Levando-se em consideração que estas variáveis são de suma importância para fins madeireiros e todos os sistemas apresentaram valores baixos, indicando significa pouco volume de madeira, observa-se que esses plantios estão sendo direcionados para a finalidade de produção de sementes.

Os sistemas 4 e 5 apresentaram as menores médias altura total e, sabendo que a altura é a variável menos influenciada pela competição podemos supor que esse resultado pode estar relacionado a condução destes plantios, valores que poderiam ser melhorados com a adoção de correção e adubação do solo e tratamentos silviculturais que favoreçam o desenvolvimento dessas plantas.

Ao se observar os sistemas com maiores valores nas variáveis AT e DAP, sistemas 1, 2 e 3, observa-se a variação entre os níveis de homogeneidade do desvio padrão, onde o sistema 1 é mais homogêneo de todos, seguido pelo sistema 3 e por fim o sistema 2. Essas variações podem estar associadas as interferências no desenvolvimento das plantas ocasionados pela competição de espaço nos sistemas. O sistema 1 , composto por abacaxi e cumaru, mesmo que com menor espaçamento entre árvores, dispôs de menor competição no início do crescimento das plantas, influenciando em um crescimento mais homogêneo se comparado com o sistema 2 de maior heterogeneidade, que dispõe de um maior número de espécie de maior porte, desde de sua inserção, o que pode gerar maior competição e entre espécie. Deste modo dependendo da competição por luz, espaço e nutrientes que o indivíduo vá passar na fase inicial da vida pode influenciar em seu crescimento e forma (Macedo, 2008).

O sistema 1 e 2 (6 e 7 anos) apresentaram as maiores médias para IMAh que não diferiram significativamente entre si, sendo $1,35 \mathrm{~m} \cdot$ ano $^{-1}$ e 1,41 m.ano ${ }^{-1}$, respectivamente (Tabela 3 ). Os plantios com idade de 8 e 10 anos (sistema 4 e 5) apresentaram as menores médias para esse índice o que, mais uma vez, evidencia que estes dois plantios têm condição inferior de sítio, além das limitações que ocorreram na área com manutenção e condução.

Tabela 3. Médias de incremento médio anual da altura (IMAh) e de incremento médio anual em diâmetro (IMAd) para Dipteryx odorata (Cumaru) em povoamentos florestais no Oeste do Pará. Onde: médias seguidas de mesma letra, na linha, não diferem estatisticamente entre si pelo teste de Tukey a 5\% de probabilidade.

\begin{tabular}{cccccc}
\hline \multirow{2}{*}{ Indice } & \multicolumn{5}{c}{ Sistema } \\
\cline { 2 - 6 } & $\mathbf{1}$ & $\mathbf{2}$ & $\mathbf{3}$ & $\mathbf{4}$ & $\mathbf{5}$ \\
\hline IMAh & $1,6 \mathrm{a}$ & $1,4 \mathrm{a}$ & $1,1 \mathrm{~b}$ & $0,7 \mathrm{c}$ & $0,7 \mathrm{c}$ \\
IMAd & $1,5 \mathrm{a}$ & $1,8 \mathrm{a}$ & $1,6 \mathrm{a}$ & $0,8 \mathrm{~b}$ & $0,9 \mathrm{~b}$ \\
\hline
\end{tabular}

Para o IMAd o sistema 2 apresentou a maior média com $1,76 \mathrm{~cm} \cdot \mathrm{cno}^{-1}$, no entanto não houve diferença significativa comparado aos sistemas 1 e 3 (6 e 9 anos), apresentando diferença significativa apenas com os sistemas 4 e 5 , que apresentaram as menores médias $0,79 \mathrm{~cm}^{-a_{0}{ }^{-1}}$ e $0,88 \mathrm{~cm}^{-a_{0} o^{-1}}$ respectivamente. Pode-se aferir por estes valores que os espaçamentos que mais se adequam, neste caso, para a produção, sejam de fruto ou madeira, devem ser os dos sistemas 2 e 3 , pois os mesmos tem os melhores valores de IMA para ambas as variáveis. Eles se apresentam em uma faixa satisfatória de incremento em que os maiores e menores espaçamentos não alcançaram. Recorda-se que devese considerar além do espaçamento de plantio e material genético, que a variação de produção pode estar associada ao material de origem do solo e seus níveis de nutrição (Vale Júnior et al. 2011).

Para ambos os índices (IMAh e IMAd) o sistema 4, consórcio de cumaru com limão, obteve as menores taxas de incremento. Sabendo que em plantios mais jovens apresentam um maior incremento médio anual, comportamento não observado neste estudo, pode-se supor que a baixa taxa deste índice pode estar relacionada com o sítio haja vista que esse é um fator muito importante para esse índice.

As variáveis morfométricas tem relação direta com as variáveis AT, DC e DAP, respondendo a elas e variando com a idade da planta e com fatores que incidem sobre ela, como espaçamento, competição entre copas, tratamentos silviculturais (desbaste ou desrama) e condições de clima e solo (Condé et al. 2013). Observa-se deste modo que algumas variáveis seguem respondendo diretamente a essa relação como o caso de maior o DAP gerar menor o GE, ou ainda, não seguirem esta relação como nos casos de FC, IA e IS que não seguem a hierarquia de maior para menor de AT, DC e CC, 
possivelmente distorcidos pelos fatores de campo como espaçamento e tratos silviculturais.

$\mathrm{Na}$ Tabela 4 observa-se as variáveis morfométricas para os plantios de cumaru. Destacase os valores de GE apresentados pelo sistema 1 e 3 (93 e 69,7, respectivamente) indicando ser o plantio com a maior e menor fragilidade. O GE tem a premissa de que quanto maior o seu valor maior a instabilidade da árvore (Durlo e Denardi, 1998) refletindo sua estabilidade principalmente em relação impacto do vento pelo risco de quebra do fuste e copa (Costa et al. 2009). Segundo Tonini et al (2008), em trabalho com castanha-do-Brasil, árvores com maiores níveis de produtividade em frutos apresentam menores valores para GE, o que indicaria, para este trabalho, o sistema 3 como o de melhor desempenho para produção de sementes

Tabela 4. Variáveis morfométricas de formal de copa (FC), grau de esbeltez (GE), índice de abrangência (IA) e índice de saliência (IS) da espécie Dipteryx odorata (Cumaru) em povoamentos florestais no Oeste do Pará.

\begin{tabular}{cccccccccccccc}
\hline \multirow{2}{*}{ Sistema } & \multicolumn{3}{c}{ FC } & \multicolumn{3}{c}{ GE } & \multicolumn{3}{c}{ IA } & \multicolumn{3}{c}{ IS } \\
\cline { 2 - 44 } & Med & Min & Max & Med & Min & Max & Med & Min & Max & Med & Min & Max \\
\hline 1 & 0,9 & 0,6 & 1,1 & 93,0 & 65,7 & 126,7 & 0,6 & 0,5 & 0,8 & 59,0 & 37,3 & 78,6 \\
2 & 0,8 & 0,4 & 1,2 & 82,8 & 59,5 & 125,4 & 0,5 & 0,2 & 0,7 & 39,5 & 23,5 & 67,0 \\
3 & 0,9 & 0,8 & 1,5 & 69,7 & 48,5 & 98,2 & 0,8 & 0,6 & 1,3 & 52,8 & 35,2 & 73,4 \\
4 & 1,2 & 0,6 & 1,9 & 90,7 & 59,9 & 197,4 & 0,6 & 0,3 & 1,1 & 52,3 & 30,7 & 162,1 \\
5 & 1,0 & 0,4 & 1,7 & 84,2 & 57,3 & 130,6 & 0,6 & 0,3 & 0,8 & 47,8 & 23,0 & 72,2 \\
\hline
\end{tabular}

As médias de GE encontradas para os demais sistemas foram altas $(82,8$ a 92,9$)$, valores próximos ao encontrado por Baloneque (2017), para a mesma espécie, em um sistema silvipastoril, que apresentou 91,7 para este índice. Assim que estes plantios se apresentam muito instáveis quando relacionados a fatores externos, sendo aconselhado a prática do desbaste. Condé et al. (2013) sugerem que espécies com o grau de esbeltez elevado não devem ser plantadas nas bordas. Essa recomendação é devida as espécies possuírem copas frondosas em que, no caso de ventos fortes, ocasionaria a quebra do fuste por conta do peso da copa.

Altos valores de GE podem estar ligados a falta de luz devido à competição entre as árvores que gera inibição do crescimento em diâmetro (Lanzarin 2016) e configuram como um indicativo da necessidade de supressão de vegetação adjacente a estas árvores (Roman et al 2009) o que nos leva a preconizar necessidade de intervenção no sistema 1 . Os tratamentos silviculturais, a exemplo de desbastes de condução, são considerados essenciais para maior produtividade e qualidade às árvores remanescentes (Santos et al. 2015). Não há estudos sobre a alelopatia do cumaru, no entanto esses efeitos não são descartados haja vista que algumas espécies florestais apresentam essa característica.

Os valores de FC, para todos os sistemas, apresentaram valores de 0,8 a 1,2 sendo o sistema 4 que apresentou o maior valor. Para esta variável valores baixos (menores que 1) indicam árvores com copas esbeltas, enquanto valores altos (maiores que 1) indicam copas achatadas e quanto menor esse valor, mais produtiva será a árvore (Orellana e Koehler 2008). Desta forma constata-se que nos povoamentos estudados existem tanto copas esbeltas, quanto arredondadas, o que pode explicar esse fenômeno é adoção de tratamentos silviculturais, como a poda que altera a forma das copas.

O sistema 2 com 0,8 de FC é o sistema que se apresenta mais produtivo pois apresenta a menor média, assim como também as copas mais esbeltas. Comparado aos demais, o menos produtivo é o sistema 4 que apresentou média 1,20 e copas mais arredondadas, isso pode ser explicado pela falta de tratamento silvicultural e competição.

As médias do IA, que se conceitua como a razão entre o diâmetro de copa e altura total, variou entre 0,49 e 0,77 , sendo que o sistema 2 e 3 apresentaram a menor e maior média, respectivamente. Este índice é importante pois conforme ocorre aumento da altura da arvore há necessidade de um espaço maior entre elas para desenvolvimento em diâmetro (Klein et al. 2017).

Durlo e Denardi (1998), em trabalho sobre a espécie Cabralea canjerana, encontraram um valor de 0,33 para o índice de abrangência, afirmando que esse índice pode ser utilizado como indicador da necessidade de intervenções silviculturais, informando o número de árvores que podem pertencer a um hectare sem sofrer concorrência.

Segundo Durlo e Denardi (1998) o IS pode ser utilizado para prever o número máximo de árvores por unidade de área e para avaliar a taxa de crescimento das espécies. Os sistemas estudados apresentam médias entre 39,5 a 59,0, indicando baixa taxa de crescimento, pois, segundo Dawkins (1963), espécies que apresentam valores de IS maiores do que 25 apresentam característica de lento crescimento.

Em relação às variáveis $\mathrm{CC}, \mathrm{AC}$ e $\mathrm{PC}$, todas relacionadas a copa das árvores, o sistema 3 se 
Silva et al.

destacou aos demais, apresentando as maiores

médias para as três variáveis (Tabela 5).

Tabela 5. Variáveis morfométricas comprimento de copa (CC), área de copa (AC) e proporção de copa (PC) da espécie Dipteryx odorata (Cumaru) em povoamentos florestais no Oeste do Pará

\begin{tabular}{cccccccccc}
\hline \multirow{2}{*}{ Sistema } & \multicolumn{3}{c}{$\mathbf{C C}(\mathbf{m})$} & \multicolumn{3}{c}{$\mathbf{A C}\left(\mathbf{m}^{2}\right)$} & \multicolumn{3}{c}{ PC $(\boldsymbol{\%})$} \\
\cline { 2 - 11 } & Med & Min & Max & Med & Min & Max & Med & Min & Max \\
\hline 1 & 6,0 & 3,6 & 7,6 & 21,3 & 10,4 & 31,2 & 74,3 & 62,5 & 83,3 \\
2 & 6,4 & 1,6 & 9,3 & 20,0 & 1,7 & 39,6 & 63,4 & 26,7 & 78,3 \\
3 & 7,8 & 5,3 & 10,1 & 41,7 & 24,6 & 58,8 & 75,0 & 81,4 & 89,1 \\
4 & 2,7 & 0,8 & 7,6 & 9,6 & 1,1 & 46,2 & 49,4 & 28,6 & 82,6 \\
5 & 4,5 & 1,9 & 6,8 & 14,4 & 2,1 & 27,8 & 62,9 & 44,2 & 90,9 \\
\hline
\end{tabular}

Para CC a maior média encontrada foi no sistema 3 apresentando média de $7,83 \mathrm{~m}$ e o valor mínimo foi verificado no sistema $4(0,80 \mathrm{~m})$. Durlo e Denardi (1998) encontraram uma média de 4,3 m para o diâmetro da copa de Cabralea canjerana. Roman et al. (2009) em estudo sobre morfometria de Cordia trichotoma encontraram uma variação do comprimento de copa entre 2,7 a 11,5 m.

Comprimentos de copa menores indicam indivíduos que possuem maior fuste aproveitável, isso aponta a ocorrência de desrama nestes indivíduos e a redução de fotossíntese o que pode comprometer as taxas de incremento e o crescimento, já um índice maior indica indivíduos de menor diâmetro, jovens, com maior proporção de copa e copas arredondadas (Klein et al. 2017).

Para AC dos indivíduos amostrados houve uma variação da média entre $9,57 \mathrm{~m}^{2}$ (sistema 4) a $41,72 \mathrm{~m}^{2}$ no sistema 3. É esperado copas frondosas para a produção de sementes, como identificado no sistema 3. Sabendo da importância da extração desses produtos para a sustentabilidades Condé et al. (2013) comenta que a extração de produtos não madeireiros é fundamental para diversificar o manejo florestal ou manejo do sistema agroflorestal, possibilitando o uso múltiplo do ecossistema.

A proporção de copa (PC) ou porcentagem de copa, juntamente com características qualitativas da copa, é um indicador da vitalidade das árvores e quanto maior a porcentagem maior será a produção (Roman et al. 2009). Neste trabalho o sistema 3 apresentou a maior média alcançando $75 \%$, média semelhante ao encontrados para outras espécies florestais estudadas por Condé et al. (2013) que informa ainda que para produtos não madeireiros uma alta relação dessa variável é desejável.

\section{Conclusões}

Com base nas características morfométricas apresentadas foi constatado que todos os sistemas analisados têm como finalidade a produção de sementes, corroborando com a finalidade de uso obtida em entrevista com os produtores rurais.
Os sistemas 4 e 5 apresentaram os menores índices para a maioria das variáveis morfométricas estudadas indicando que escolha do local, arranjo e o manejo dos plantios de cumaru é imprescindível para o desenvolvimento da espécie.

Os melhores valores para plantios de cumaru foram identificados nos sistemas 2 e 3 indicando que estes arranjos podem apontar um bom desenvolvimento da espécie em sistema agroflorestal na região.

\section{Agradecimentos}

À Universidade Federal do Oeste do Pará e ao Instituto de Biodiversidade e Florestas pela oportunidade realizar este trabalho. Aos produtores rurais visitados durante a coleta dos dados, pela atenção, informações e hospitalidade. À Secretaria de agricultura de Alenquer e ao técnico Elinaldo Maia pelo apoio durante a coletas dos dados.

\section{Referências}

Alvares CA, Stape JL, Sentelhas PC, Gonçalves, JLM, Sparovek, G (2013) Koppen's climate classification map for Brazil. Zeitschrift Meteorologische Vol. 22(6): p. 711 - 728.

Baloneque DD (2017) Variáveis morfométricas de quatro espécies florestais em sistema silvipastoril no município de Belterra, Pará. Trabalho de conclusão de curso, Instituto de biodiversidade e florestas, Universidade Federal do Oeste do Pará. 25p.

Capucho HLV, Rebelo ADM, Pauletto D, Silva AR, Paiva Neto V (2016) Morfometria de Dipteryx spp. em sistemas agroflorestais em Belterra e Mojuí dos campos - Pará. In: X Congresso de sistemas agroflorestais Cuiabá, Mato Grosso, Brasil.

Carvalho PER (2009) Cumaru-Ferro Dipteryx odorata. Embrapa Florestas, Comunicado Técnico. $8 p$.

Condé TM, Lima MLM, Lima Neto EM Tonini H (2013) Morfometria de quatro espécies florestais em 
sistemas agroflorestais no munícipio de Porto Velho. Agroambiente On-line, 7(1): 18-27.

Costa JR, Castro ABC, Wandelli EV, Coral, SCT, Souza SAG (2009) Aspectos silviculturais da castanha-do-brasil (Bertholletia excelsa) em sistemas agroflorestais na Amazônia Central. Acta Amazônica, 39(4): 843-850.

Dawkins HC (1963) Crow diameters: their relation to bole diameter in tropical Forest trees. Commonw Forest Review, 42(4): 318-333.

Dionísio LFS, Araújo HXD, Correia RG, Martins WBR, Costa JSD, Maciel FCDS (2018) Influência do Primeiro Desbaste na Morfometria de Tectona grandis L.f. em Roraima. Floresta e Ambiente, 25(1): e00118214.

Durlo MA (2001) Relações morfométricas para Cabralea canjerana (Well.) Mart. Ciência Florestal, 11(1):141-149.

Durlo MA, Denardi L (1998) Morfometria de Cabralea canjerana, em mata secundária nativa do Rio Grande do Sul. Ciência Florestal, 8(1): 55-66.

EMBRAPA. Empresa Brasileira de pesquisa agropecuária (2016) Mapas de solos e aptidão agrícola das áreas alteradas do estado do Pará. Disponível em: < https://www.embrapa.br/documents/1354300/0/Ma pas+de+solos+e+aptid \%C3\% A3o+agr\%C3\%ADco la+das+\%C3\%A1reas+alteradas+do+Par\%C3\%A1/ 80b10a04-8d10-419a-918d-8b22773ee44a>.

Acesso em: 20 de junho de 2019.

Ferreira GC, Hopkins MJG, Secc RDS (2004) Contribuição ao conhecimento morfológico das espécies de leguminosa e comercializadas no estado do Pará, como "angelim". Acta Amazônica, 34(2): 219-232.

Gonçalves DCM, Gama JRDV, Oliveira FDA, Júnior RCDO, Araújo GC, Almeida LSD (2012) Aspectos Mercadológicos dos Produtos não Madeireiros na Economia de Santarém-Parál. Floresta e Ambiente, 19(1): 9-16.

IBGE - Instituto Brasileiro de Geografia e Estatística (2016) Produção da extração vegetal e silvicultura. v. 31:1-54p. Disponível em: https://biblioteca.ibge.gov.br/visualizacao/periodico s/74/pevs_2016_v31.pdf. Acesso em: 20 de junho de 2019. ISSN: 0103-8435.

IBGE. Instituto Brasileiro de Geografia e Estatística (2004) Mapa de Vegetação do Brasil. Escala: 1:5.000.000. Disponível em: $<$ https://www.mma.gov.br/estruturas/sbf_chm_rbbi o/_arquivos/mapas_cobertura_vegetal.pdf $>$. Acesso em: 20 de junho de 2019.

Klein DR, Hess AF, Krefta SM, Vieira Filho MDH, Ciarnoscki LD, Costa EA (2017) Relações morfométricas para Araucaria angustifolia (Bertol.) Kuntze em Santa Catarina. Floresta, 47(4): 501-512.

Lima Júnior JFMD, Barbosa AP, Lopes RBC (2009) Análise do crescimento do cumaru (dipteryx odorata aubl. Willd) e jatobá (hymenaea courbaril 1. Varo courbaril) em plantios puros e mistos em recuperação de áreas degradadas pela pecuária extensiva. Manaus. In: XVIII Jornada de iniciação científica PIBIC CNPq/FAPEAM/INPA, Manaus, Brasil.

Lanzarin K (2016) Relações Morfométricas e Potencial de Manejo de Maclura tinctoria (L.) D. Don Ex. Steud em Formações Secundárias do Noroeste do rio Grande do Sul. Dissertação, Universidade Federal de Santa Maria. 77p.

Loureiro AA, Silva MF, Alencar JDC (1979) Essências madeireiras da Amazônia. INPA, Manaus: CNPq/INPA/SUFRAMA. Boletim de Pesquisa. $245 \mathrm{p}$.

Macedo JLV (2008) Cultivo de fruteiras em sistemas agroflorestais. In: Embrapa Amazônia OcidentalArtigo em anais de congresso (ALICE). In: Encontro de Frutas Nativas do Norte e Nordeste Do Brasil, 1., 2008, São Luís. Frutas nativas: novos sabores para o mundo. São Luís: UEMA: SBF: EMBRAPA: SEBRAE: SEAGRO, 2008. 1 CD-ROM.

Moreira JMMAP, Simioni FJ, Oliveira EB (2017) Importância e desempenho das florestas plantadas no contexto do agronegócio brasileiro. Floresta, 47(1): 85-94.

Orellana, E, Koehler AB (2008) Relações morfométricas de Ocotea odorífera (Vell). Rohwer. Revista Acadêmica Ciências Agrárias e Ambientais, 6(2):229-237.

Rêgo LJS (2014) Análise econômica da produção da amêndoa de cumaru e caracterização do seu mercado em Santarém e Alenquer, Pará. Dissertação, Universidade Federal de Viçosa. 141p.

Roman M, Bressan DA, Durlo MA (2009) Variáveis morfométricas e relações interdimensionais para Cordia trichotoma (Vell.) Arráb. ex Steud. Ciência Florestal, 19(4): 473-480.

Santos ATD, Mattos PPD Braz EM Rosot NC (2015) Determinação da época de desbaste pela análise dendrocronológica e morfométrica de Ocotea porosa 
(nees \& mart.) Barroso em povoamento não manejado. Ciência Florestal, 25(3): 699-709.

Santos SHM (2002) Cumaru Dipteryx odorata Wild. Família Leguminosae. Belém: Embrapa Amazônia Oriental, (Recomendações Técnicas). 4p.

Silva AF, Pauletto D, Capucho HLV, Sousa VS, Silva AR, Pimentel CR (2018) Produção e renda do componente arbóreo cumaru (Dipteryx spp.) em sistemas agroflorestais na região Oeste do Pará. Caderno de Pesquisa, Ciência e Inovação, 1(3): 99109.

Silva TM, Da Silva Jardim FC, da Serra Silva M, Shanley P (2010) O Mercado de Amêndoas de Dipteryx odorata (Cumaru) no Estado do Pará. Floresta 40(3): 603-614.

Silvestre S (2006) Árvores da Amazônia. São Paulo. Empresa das artes. 248p.

Tonini H, Arco-Verde MF (2005) Morfologia da copa para avaliar o espaço vital de quatro espécies nativas da Amazônia. Pesquisa agropecuária brasileira, Brasília, 40(7):633-638.

Tonini H, Junior MMCO, Schwengber D 2008 Crescimento de espécies nativas da amazônia submetidas ao plantio no Estado de Roraima. Ciência Florestal, 18 (2): 151-158.

Vale Júnior JF, Souza MIL, Nascimento PPR, Cruz DL (2011) Solos da Amazônia: etnopedologia e desenvolvimento sustentável. Revista agroambiente on-line, 5(2): 158-165. 